\title{
INVESTIGAR, INTERVIR E PRESERVAR EM HISTÓRIA DA EDUCAÇÃO
}

Por Luis A. Marques Alves y Joaquim Pintassilgo (coords). Porto: CiTCEM/ HISTEDUP, 2017, 173 páginas. ISBN 9789898351678.

Investigar, Intervir e Preservar em História da Educação, coordinado por los profesores Luis A. Marques Alves (Universidade do Porto) y Joaquim Pintassilgo (Universidade de Lisboa), recoge las intervenciones que se realizaron en el marco del XI Congresso Luso-Brasileiro de História da Educação (COLUBHE), promovido por la Associação de História da Educação de Portugal (HISTEDUP), la Associação Nacional de Pós-Graduação e Pesquisa em Educação (ANPEd) y la Sociedade Brasileira de História da Educação (SBHE).

El Congreso fue organizado por el Centro de Investigação Transdisciplinar "Cultura, Espaço e Memória»(CITCEM), y se celebró en la Faculdade de Letras de la Universidade do Porto (Portugal) entre los días 20 y 23 de junio de 2016 bajo el lema «Investigar, Intervir e Preservar: Caminhos da História da Educação Luso-Brasileira», donde se congregaron investigadores y docentes de las comunidades científicas de ambos países dedicados al estudio de temáticas relacionadas con la historia de la educación.

Siguiendo la propuesta temática del Congreso («Investigar como un cuadro epistemológico específico que convendrá siempre revisar y precisar. Intervenir, porque, desde hace algún tiempo, importa reivindicar un espacio de intervención social. Preservar porque en la volatilidad de las cosas importa defender la cultura material escolar y exigir su permanencia física en un mundo cada vez más virtual», como explican los profesores Alves y Pintassilgo en la Introducción), se agrupan en este trabajo una selección de los textos, dos por cada eje temático, que allí se defendieron como ponencias, además de las conferencias de inauguración y de clausura: 
La conferencia de inauguración estuvo a cargo del profesor Justino Magalhães, con el título de «Entre história e educação-historiografia e história da educação em Portugal e Brasil»(pp. 17-44). En ella, el catedrático del Instituto de Educação de Lisboa, establece relaciones entre «modernidad»e «institución educativa» en perspectiva histórica, resaltando los procesos que se observan en la transición del Antiguo Régimen; define el periodo ochocentista como un espacio cronológico con fenómenos educativos específicos y numerosas alianzas entre Portugal y Brasil, caracterizado por la permeabilidad de manifiestos, de pedagogías, de contenidos o de prácticas entre culturas hermanas:

En Europa y particularmente en Portugal y Brasil, destaca el autor, el tránsito de la Primera Modernidad es impensable sin la educación formal y sin la aculturación escrita y la institución escolar. Ese ciclo se caracterizó por la circulación de ideas y de modelos, la formación de bibliotecas, el establecimiento de Cátedras de Primeras Letras y de Escuelas, que multiplicaban la red municipal, conventual, domiciliaria. [...] La independencia aportó un Brasil soñado y un Brasil proyectado. El Brasil Moderno no dejó de ser producto también de la escuela y es impensable sin la institución-educación.

Entre la riqueza y variedad de aspectos que integran este texto, es necesario destacar el análisis sobre el estado de la Historia de la educación que experimenta, según su criterio, una apertura sistémica y una vitalidad nunca antes observada, generando como resultado nuevos paradigmas, emergiendo nuevos temas, construyendo nuevos objetos científicos, abriendo nuevos diálogos inter y transdisciplinarios, congregando nuevas fuentes históricas, presentando nuevos discursos, cursando diversas pragmáticas o de-construyendo y re-inventando nuevas fórmulas de representación. De todos modos, señala, algunas voces advierten sobre la prolijidad y debilidad en la producción como resultado de «inmediatismos y perspectivismos comprometedores, o de fragilidades en la dureza de la prueba, debidas a algún aligeramiento en la densidad de los discursos y a la elementalidad de los testimonios documentales», y mantiene que en lo que concierne a la historia del presente, la Historia de la educación «retrocede en la interdisciplinaridad y cede en 
favor de la Sociología, de la Antropología, de la Didáctica, de la administración escolar, o circunscribe la prueba a la utilización de testimonios orales».

El texto «História da educação como arqueologia: cultura material escolar e escolarização» (pp. 45-62) de Diana Gonçalves Vidal, profesora del Departamento de Filosofía de la Educación y Ciencias de la Educación de la Universidad de São Paulo, que constituyó la conferencia de clausura, se estructura en tres apartados. En el primero, «La cultura material como dominio de la historia», establece la identificación de la cultura material como categoría y fuente en la investigación en historia, en una relación que cuenta ya con una cierta tradición: «la operación historiográfica en el siglo xx no podía limitarse al uso de los documentos escritos. Estaba obligada a incluir otras fuentes en el reconocimiento de la materialidad de la experiencia humana». En el segundo apartado, "Cultura material escolar y escolarización», trata de establecer nexos identitarios entre ambos conceptos: "Pensar los objetos como constitutivos de los sujetos escolares, de sus procesos de subjetivación y como agente son contribuciones traídas por los estudios de la cultura material». En el tercero, «El historiador de la educación como arqueólogo (y antropólogo)», destaca la necesidad de establecer lazos metodológicos con la antropología y la arqueología, necesarios para el estudio de la dimensión material de la historia de la educación. Además, sostiene la autora que existe una creciente preocupación entre la comunidad iberoamericana de historia de la educación por asociar a los documentos textuales otro tipo de fuentes susceptibles de ensanchar el conocimiento que se produce en este campo. De este modo, la denominada cultura material escolar se vuelve objeto de investigación, cobrando la dimensión de categoría y fuente de información para ayudar a entender de modo más completo la historia de la escuela y del proceso de escolarización llevado a cabo, en este caso, en Portugal y en Brasil. Esta incorporación suscita entre los investigadores del campo una serie de retos teóricos y metodológicos que estimulan el diálogo interdisciplinar, en especial con la antropología y la arqueología. En este sentido, parece necesario prestar atención a las aportaciones que estos otros campos pueden ofrecer a la historia de la educación. 


\section{INVESTIGAR}

«Entre a pesquisa administrada e a prática do artesão: uma aventura, uma vontade, um projeto» de Marcus Aurelio Taborda de Oliveira (pp. 65-78), ofrece una mirada crítica sobre las exigencias que el sistema "productivista» actual impone al investigador universitario, obsesionado por los índices de impacto de la producción científica. Apunta que la investigación "administrada», condicionada por la cantidad, la premura, el volumen, el resultado y la fungibilidad dificultan otros modos de investigar, como la "práctica del artesano», necesaria para producir trabajos de mayor calidad, producto de la reflexión, el sosiego y la libertad de elección. Para investigar así son necesarios cuatro elementos fundamentales: el tiempo, el silencio, la soledad y la colaboración, y sostiene que es un problema transnacional, "por lo menos si observamos contextos como el portugués, el español, el italiano y el latino-americano de modo general», al que se ha llegado como consecuencia

de habernos dejado enredar por una forma de investigación académica, burocrática y poco intelectual [...]. Burocratizamos la investigación y nos apartamos de las preguntas, de la lectura, del trabajo metódico, del rigor, pero también de la inquietud, de la osadía, de la imaginación, de la capacidad de asumir la propia ignorancia como virtud y desafío de quien investiga.

En «O governo da cognição: emergência histórica do dispositivo curricular e pedagogização do conhecimento», Jorge Ramos do Ó (pp. 79110) centra su texto en el debate sobre la separación entre la cultura escolar y la cultura científica, entre el modo de aprender mediante la acción de investigar precedida de un «tiempo de la espera y de la duda necesario para quien desee desvelar lo oculto o prepararse para lo desconocido de modo innovador», o el de aprender mediante la acción de enseñar un conjunto predeterminado, cerrado y «lícito» de saberes «verdaderos». Este hecho es el resultado de un proceso observado en las instituciones educativas a partir del siglo XvI, donde

los emergentes sistemas de enseñanza que fueron convirtiendo a los niños y a los jóvenes en alumnos, a partir de la Reforma protestante, se convirtieron en una auténtica maquinaria escolar que subordinó de forma implacable los saberes y su transmisión 
a patrones rígidos, desde la propia enseñanza superior hasta los bancos en que se aprendían las primeras letras.

Una tradición curricular que llega hasta nuestros días, cuando es difícil encontrar formas de pensar y de trabajar alternativas «en donde el aprender se subordine efectivamente al crear y el adquirir al producir».

\section{INTERVENIR}

En «In(ter)venções: a história da educação como campo disciplinar e de pesquisa», Terciane Ângela Luchese (pp. 113-130) aborda algunas cuestiones a las que desde hace unas décadas se enfrenta, a su juicio, la disciplina de Historia de la educación: «¿Que pretenden de nosotros? ¿Qué tenemos para ofrecer? ¿Cuál es nuestra función social? ¿Cómo podemos dignificar nuestra investigación?». Parece que alguna respuesta puede apuntar hacia la intervención. Por un lado, intervenir en el campo de la investigación invirtiendo en la profundidad epistemológica y en marcos teóricos más complejos; fomentar la continuidad y la calidad de la formación de los investigadores; ampliar la presencia en las redes y espacios de discusión científica y en los de definición de políticas científicas y educativas; ampliar el trabajo cooperativo y construir relaciones de reciprocidad institucional, así como entre investigadores, y aprovechar las ventajas de los avances tecnológicos. Por otro lado, intervenir en el campo de la enseñanza, movilizando a los estudiantes hacia el aprendizaje de la Historia de la educación, creando estrategias que fomenten el pensamiento, la reflexión y la crítica posibilitando que

la enseñanza de Historia de la Educación pueda constituirse en un espacio en donde los estudiantes se reconozcan como sujetos históricos, y que, por la práctica de la investigación, del diálogo y de las intervenciones de aprendizaje, puedan ampliar los repertorios de conocimiento, las redes de significación sobre quién somos, como llegamos a lo que estamos viviendo y de qué modo construimos nuestro presente por las acciones de lo cotidiano.

Así concibe la autora la Historia de la educación: «con espíritu crítico como nos dice Duby y alertada por Febvre de que "la ciencia no se hace en una torre de marfil. Se hace a la par y al paso con la vida" ». 
En «História da educação: uma maneira de pensar para melhor intervir», David Justino (pp. 131-137) presenta cuestiones cruciales sobre la relación que existe entre investigación y enseñanza de la Historia de la educación, y la intervención cívica y social: «El historiador no es un mero coleccionador de hechos o un anticuario de fuentes», nos dice, pues su trabajo debe estar centrado en la revisión sistemática del pasado en sus múltiples construcciones y representaciones, y contextualizado por las condiciones y desafíos sociales y culturales del presente. El autor cita algunas vías sugeridas por el historiador Magalhães Godinho indispensables para resituar la historia y las ciencias humanas en el marco de la cultura científica: «desideologización, problematización y transdisciplinaridad», y sostiene que la Historia consiste en comprender los problemas actuales gracias a una indagación científica del pasado orientada a la preparación de tiempos venideros. Pero, ¿en qué medida esa comprensión nos capacita para poder intervenir en la educación, y concretamente en los problemas que esta propone? En primer lugar, «en el respeto de un protocolo donde los conceptos y los métodos son movilizados a partir de los problemas y de acuerdo con reglas consolidadas por los cuadros teóricos principales de las ciencias sociales y humanas»; en segundo lugar, "nos aproximamos decisivamente hacia el realismo teórico y metodológico que pretende identificar los mecanismos, procesos y contextos que encuadran los acontecimientos y situaciones particulares». Por último, "pensar históricamente los problemas sociales y humanos que se proyectan sobre el campo de la educación en la interacción con los otros campos: la sociología, la economía, la antropología, la comunicación y las propias tecnologías».

\section{PRESERVAR}

En «Pesquisa histórica e arquivos pessoais: o exemplo do arquivo Gustavo Copanema», Angela de Castro Gomes (pp. 141-151) reflexiona sobre el valor de uso público de los archivos personales, especialmente en lo que respecta a la preservación de la memoria, centrándose en el caso de un archivo particular. La autora divide su exposición en dos partes. Por un lado, aborda la relación existente entre el «descubrimiento» de los archivos de carácter personal ligado a las transformaciones observadas en el campo historiográfico brasileño a finales del siglo xx, que presenta «una profunda renovación teórica y metodológica de la disci- 
plina, con el reconocimiento de la legitimidad de nuevos actores, objetos y fuentes para la investigación»; por otro, resalta las características de los archivos personales, especialmente de figuras intelectuales, tomando como ejemplo el del político brasileño Gustavo Capanema (19001985), figura imprescindible en el estudio de la historia de la educación del país. Capanema era natural del Estado de Minas Gerais, del que fue gobernador en 1933 y ministro de educación en 1934.

En «Preservar a herança educativa: desafios, limites e intervenção» (pp. 153-169), Margarida Louro Felgueiras presenta dos cuestiones estrechamente relacionadas. De una parte, la preservación de la herencia educativa, en la que integra el ámbito material y el inmaterial, como tema de reflexión para los historiadores e historiadoras de la educación, en un momento de debate sobre «la problemática de las fuentes históricas en sus varios soportes»; de otra parte, explora los ejes de intervención que deben ser definidos como prioritarios para los historiadores de la educación, intentando superar la dicotomía entre historia cultural e historia social, sacando el foco del ámbito social «para crear espacio a la afirmación del material, como dimensión básica del ser humano, donde cultura y sociedad se entrelazan». Afirma la autora que el patrimonio ligado a la educación conforma un conjunto de recursos heredados que deben estar al servicio de las personas, por lo que deben ponerse en valor y tratarse de modo integrado y accesible, «como parte de su derecho de participación, como ciudadanos, en la vida cultural». Pese a ser limitada nuestra responsabilidad individual, deben señalarse los peligros y dificultades que asoman en el horizonte del espacio común. Es preciso pensar alternativas y definir estrategias colectivas que contribuyan a la solución de problemas ya identificados, entre los que se encuentran la conservación de los archivos físicos, el desarrollo de un trabajo interdisciplinario junto con otras ciencias, así como la exigencia de información pública a los investigadores sobre el acceso a estas fuentes.

Por último, al final del libro se recogen unas breves notas biográficas sobre los autores y autoras de los textos que lo componen.

Xosé M. Malheiro Gutiérrez Universidade da Coruña xmalheiro@udc.es 